\title{
Basally Osseointegrated Implants as a Viable Immediate Solution in Cases of Failed Implants in Atrophic Posterior Maxillary Region: A Case Report
}

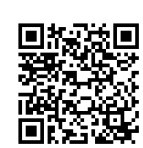

\author{
Vaibhav Nagaraj ${ }^{3 *}$, Sudhakara Reddy $\mathrm{K}^{1}$, Thokala Dhamodaran ${ }^{2}$ and Swarna Sudeeshna ${ }^{4}$ \\ ${ }^{1}$ Department of Oral \& Maxillofacial Surgery, Sri Rajiv Gandhi College of dental sciences, India \\ ${ }^{2}$ Department of Conservative \& Endodotics, Raja Rajeswari Dental College, India \\ ${ }^{3}$ Department of Oral \& Maxillofacial Surgery, India \\ ${ }^{4}$ D Private Practitioner, India
}

Submission: February 07, 2017; Published: February 19, 2018

*Corresponding author: Vaibhav N, Department of Oral \& Maxillofacial Surgery, Sri Rajiv Gandhi College of Dental Sciences,India,Tel:+919844258076; Email: vaibsarticles@gmail.com

\begin{abstract}
Basal implants are gaining popularity at recent times and emerging as alternate option to avoid sinus lift and other grafting procedures. Due to their unique design of horizontal disc component which gets engaged in basal cortical bone, they can be installed even in those cases, where the vertical bone supply is reduced such as moderate to severe atrophic ridges.

This article describes the placement of basal implant in a case where conventional dental implant done along with indirect sinus lift was a failure. Since the possibility of mounting prosthesis does not depend on the presence of vertical/alveolar bone, they can be restored immediately. Two years follow up showed successful osseointigration of basal implant without any loss of bone.
\end{abstract}

Keywords: Basal implants; Disc implants; Implant without sinus lift; BOI implants

\section{Introduction}

Posterior maxilla often presents with several challenging situations for placement of implants because of its anatomical limitations. Poor bone quality combined with inadequate bone volume because of position of the floor of the sinus as well as resorption of the alveolar bone make conditions for implant placement less favorable in the region [1]. Sinus lift with bone augmentation [2], is one of the most predictable alternatives for increasing subantral bone height to place implants. Since the first description [3] of subantral augmentation by Tatum and modified by Boyne, there were several modifications published in the literature. However, Sinus lift procedure has its limitations. It is invasive surgical procedure with complications [4] like membrane perforation, bleeding, postoperative infection and also donor site morbidity in case of autogenous grafting. They also increase both cost and treatment time [5]. Even survival rate of implant [6] placed in augmented sinus area has wide range from $36 \%$ $-100 \%$. Implant ologists are facing the increased demand for alternate options with fixed restoration in short term treatment protocols with affordable cost without additional surgeries. Laterally inserted basal osseointigrated implants not only avoid any additional surgical procedures but also provide reliable anchor in basal cortical bone even in less vertical bone height and can be loaded immediately without waiting period of 3-6 months. Masticatory load transmission [7] is confined to the horizontal implant segment sand essentially to the cortical bone Structures. This virtually eliminates the need for vertical bone augmentation procedures.

We present a case in which patient had been treated previously with indirect sinus lift simultaneous implant placement was a failure within 3 months. With residual bone height of $3 \mathrm{~mm}$ after removing failed implant, we placed laterally inserted basal osseointigrated implant with immediate loading. Post two years follow up showed no bone loss and no signs of failure. This report highlights the indications and advantages of basalosseo integrated implants in cases with inadequate bone height in posterior maxillary region.

\section{Case report}

A 40 year old male patient has come with a chief complaint of missing upper left first molar tooth and wanted to get it replaced. A cone beam computed tomography (CBCT) image of that region revealed that the available bone height was $6 \mathrm{~mm}$ (Figure 1). 


\section{Advances in Dentistry \& Oral Health}

Subsequently an 'indirect' sinus lift procedure was planned and executed. A bone height of $9 \mathrm{~mm}$ was achieved by using calciumPhosphosilicate bone graft material (Nova Bone Dental Putty ${ }^{\circledR}$ ) for augmentation. Simultaneously a 4.2 × $8 \mathrm{~mm}$ crestal type cylindrical implant $\left(\right.$ Hitech ${ }^{\circledR}$, Herzlia, Israel) was placed. After a period of 3 months follow up, implant failure was noticed by an intraoral peri-apical (IOPA) radiograph that showed bone loss around the implant (Figure 2). The failed implant was retrieved and the area was curetted and cleaned. Radiographs after 2 months of implant retrieval revealed a residual bone height of only $4 \mathrm{~mm}$.
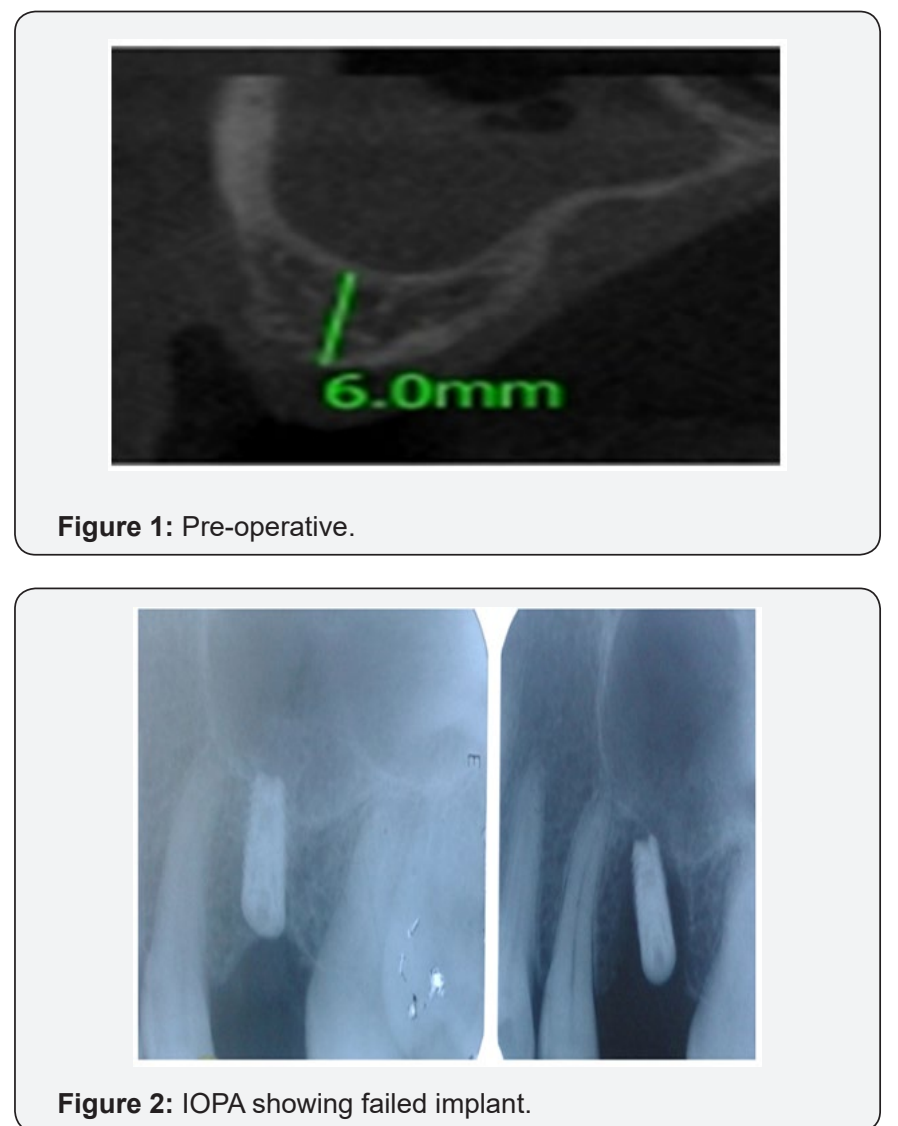

The situation and prognosis was then explained to the patient. The patient refused to undergo further surgical augmentation procedures and wasn't too keen on waiting longer to get the final prosthesis. So, a decision was taken to place a Basal Osseointegrated Implant' BOI in the upper left first molar region with immediate loading. A crestal incision was given along with mesial and distal release incisions. Buccalmucoperiosteal flap was reflected. A vertical cut was given on the buccal aspect of the bone below the imaginary line depicting the sinus lining extending till the lower border of alveolar bone on the buccal aspect using a VC 1.6 straight long bur attached to contra-angled hand-piece. Care should be taken not to perforate the palatal wall. Then, a horizontal cut is made on the upper border of the vertical cut using a ' $\mathrm{T}$ ' shaped bur. During this process, the vertical component of the ' $\mathrm{T}$ ' shaped bur corresponds to the groove of the previously created vertical cut. At this point, a BOI@- BS9 implant (IHDE
Dental $®$, Gommiswald Switzerland) was placed in the ' $\mathrm{T}$ ' shaped groove that was created (Figure 3). It was then gently tapped with a mallet to ensure proper seating of the implant within the groove. The stability of the implant was then checked, the flap was sutured back in position and an impression was taken after a week (Figure 4).

After 2 weeks of placement, the implant was loaded with a metal ceramic crown (Figure 5). The patient was followed up regularly. The patient had no specific complaints. Two years follow-up findings showed (Figure 6) successful osseointegration with no bone loss and no implant associated complications with complete patient satisfaction.
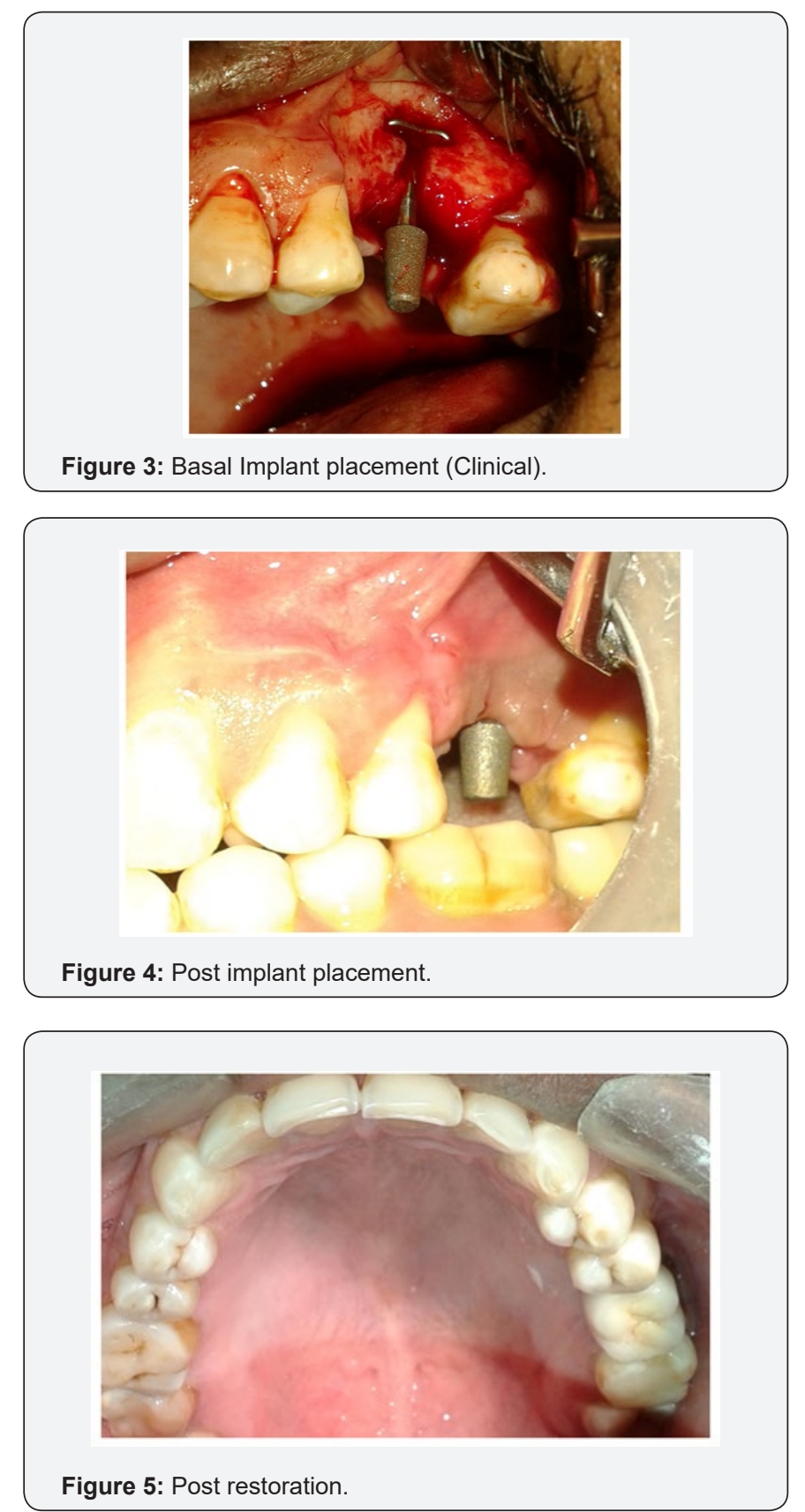


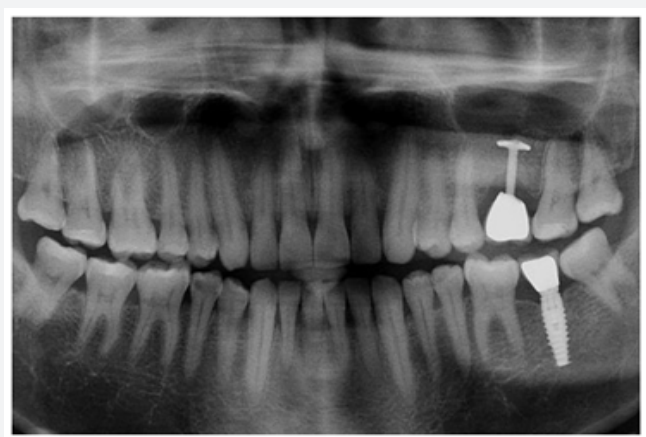

Figure 6: 2 year follow up OPG.

\section{Discussion}

Conventional 'crestal' implants require good bone height and width. But resorption following the extraction of posterior maxillary teeth sometimes results in severe loss of bone in vertical and or horizontal dimensions which may compromise the use of conventional dental implants [8]. Various sinus augmentation [9] procedures have been used with varying amounts of success. But, the invasiveness of these procedures not only adds local complications like mucosal perforation [10], acute sinusitis [11] etc but also economical burden to the patient. In severely resorbed cases, Grafting with sinus lift most often accomplished as part of a 2-stage implant protocol which is followed by a 3- to 6-month healing period to allow for maturation of the graft prior to the placement of dental implants. The total time taken for completion of treatment with prosthesis delivery can take up to a year.

Dental implants for insertion from the lateral aspects of the jaw bone have been described repeatedly, since 1972 [12]. The term basal implant refers to the principles of utilizing basal bone and cortical areas free of infection and resorption. This rationale stems from orthopedic surgery and from the experience that cortical areas are more resistant against resorption [13,14]

Usage of basal implants virtually precludes the need for sinus lifts or other bone augmentation procedures. This reduces morbidity as well as the duration of the rehabilitation procedure.

These basal osseointigrated implants offer several other advantages. No masticatory forces need to be transmitted to the bone via vertical aspects of the implant. It is confined to the horizontal implant segments. The positive retention in the bone is created in the cortical bone region. Implant failure due to infections is pretty rare because the load transmission is supposed to occur within the basal aspect of the implant, far away from the site of bacterial infection from the oral cavity [14]. They can also be used where very little vertical bone is present, while the supply of horizontal bone is still sufficient or can even use trans-sinusly.

Peri-implantitis [15] is a real issue around crestal implants. Once a 'crestal' implant is inserted, it completely obturates the osteotomy site. Any infection carried into the bone intraoperatively or preoperatively can endanger the therapeutic result considerably leading to an implant failure. Presumably, the prognosis of BOI implants is considered better because the blood supply to the bone remains undisturbed because of the 'skeletalized' enossal implant fixture [8]. It is assumed that the incidence of periimplantitis is very less compare to conventional implants due to smooth surface vertical component (no surface enlargement) of the implant which eliminates bacterial attraction. With integrated basal implants, infection originating in the oral cavity would not normally be expected to spread endosseously, for as long as the implants are not mobile to the extent that they can be intruded. In cases infections sets in because of improper hygiene or food retention, it spreads submucosally which is easier to treat rather than intra-osseously.

The concept of immediately loading implants [16] has been well documented in the literature. The maxillary arch poses difficulties for immediate loading than mandible. The presence of type III and IV bone predominantly as well as the presence of the maxillary sinus makes the prognosis of immediate loading implants rather questionable in the posterior maxilla [17]. Basal implants which are inserted laterally, can be loaded immediately which shows adequate anchorage and osseointegration in completely edentulous maxilla [19-21].

The maximum stresses are always located near the baseplates. So the stress distribution is more even in basal implants than conventional implants [20].

\section{Conclusion}

Basal implants are gaining popularity in recent times due to its advantages of managing atrophic cases, immediate loading, lack of periimplantitis and no additional expensive grafting procedures. This case report shows failed case of indirect sinus lift with conventional implant was successfully treated with laterally inserted basal implant along with immediate loading without any grafting procedures even in $4 \mathrm{~mm}$ the residual bone below the sinus. Two years follow up showed successful osseointigration without any signs of failure with no marginal bone loss noted. Conventional implants are the first choice in normal bone conditions but single stage basal implants should be option in cases where conventional implant failure and in cases where residual bone height was very less as in moderately or severely atrophied ridges. Still long term follow ups, larger group studies and comparative studies are required further.

\section{References}

1. Rodoni LR, Glauser R, Feloutzis A, Hammerle CH (2005) Implants in the Posterior Maxilla: A Comparative Clinical and Radiologic Study. Int J Oral Maxillofac Implants 20(2): 231-237.

2. Misch CE (1987) Maxillary sinus augmentation for endosteal implants: Organized alternative treatment plans. Int J Oral Implantol 4(2): 49-58

3. Rao GS, Reddy SK (2014) Antral balloon sinus elevation and grafting prior to dental implant placement: review of 34 cases. Int J Oral Maxillofac Implants 29(2): 414-418. 
4. Kfir E, Kfir V, Eliav E, Kaluski E (2007) Minimally invasive antral membrane balloon elevation: Report of 36 procedures. J Periodontol 78(10): 2032-2035

5. Sherry JS, Balshi TJ, Sims LO, Balshi SF (2010) Treatment of a severely atrophic maxilla using an immediately loaded, implant-supported fixed prosthesis without the use of bone grafts: a clinical report. J Prosthet Dent 103(3): 133-138.

6. Graziani F, Donos N, Needleman I, Gabriele M, Tonetti M (2004) Comparison of implant survival following sinus floor augmentation procedures with implants placed in pristine posterior maxillary bone: a systematic review. Clin Oral Implants Res 15(6): 677-682.

7. Ihde S (2001) Restoration of the atrophied mandible using basal osseointegrated implants and fixed prosthetic superstructures. Implant Dent 10(1): 41-45.

8. Lundgren S, Cricchio G, Palma VC, Salata LA, Sennerby L (2008) Sinus membrane elevation and simultaneous insertion of dental implants: a new surgical technique in maxillary sinus floor augmentation. Periodontol 47: 193-205.

9. Fugazzotto PA,Vlassis J (2005) Long-term success of sinus augmentation using various surgical approaches and grafting materials. Int J Oral Maxillofac Implants 13(1): 52-58.

10. Biglioli F, Pedrazzoli M, Colletti G (2010) Repair of a perforated sinus membrane with a palatal fibromucosal graft: a case report. Minerva Stomatol 59(5): 299-304

11. Alkan A, Celebi N, Baş B (2008) Acute maxillary sinusitis associated with internal sinus lifting: report of a case. Eur J Dent 2(1): 69-72.

12. Ihde S, Eber M (2004) Case report: restoration of edentulous mandible with 4 BOI implants in an immediate load procedure. Biomed Pap Med
Fac Univ Palacky Olomouc Czech Repub 148(2): 195-198.

13. Stefan Ihde (2009) Comparison of basal and crestal implants and their modus of application. Smile Dental Journal 4(1): 36-46.

14. Ihde, Stefan (2005) Principles of BOI: Clinical, Scientific, and Practical Guidelines to 4-D Dental Implantology. Springer.

15. Zurdo J, Romão C, WennströmJL (2009) Survival and complication rates of implant-supported fixed partial dentures with cantilevers: a systematic review. Clin Oral Implants Res 20(Suppl) 4: 59-66.

16. De Bruyn H, Raes S, Ostman PO, Cosyn J (2004) Immediate loading in partially and completely edentulous jaws: a review of the literature with clinical guidelines. Periodontol 66(1): 153-187.

17. Becker W, Becker BE, Israelson $H$, Lucchini JP, Handelsman $M$, et al. (1997) One-step surgical placement of Branemarkim plants: a prospective clinical multicenter study. Int J Oral Maxillofac Implants 12: 454-462.

18. Tarnow DP, Emtiaz S Classi A (1997) Immediate loading of threaded implants at stage 1 surgery in edentulous arches: ten consecutive case reports with 1 to 5 years data. Int J Oral Maxillofac Implants 12(3): 319-324.

19. Odin G, Misch CE, Binderman I, Scortecci G (2012) Fixed rehabilitation of severely atrophic jaws using immediately loaded basal disk implants after in situ bone activation. J Oral Implantol 38(5): 611-616.

20. Goldmann T, Ihde S, Kuzelka J, HimmlovaL (2008) Bendable vs Angulated dental implants: consideration of elastic and plastic material properties based on experimental implant material data. Biomed Pap Med Fac Univ Palacky Olomouc Czech Repub 152(2): 309-316.

\section{Your next submission with Juniper Publishers will reach you the below assets}

- Quality Editorial service

- Swift Peer Review

- Reprints availability

- E-prints Service

- Manuscript Podcast for convenient understanding

- Global attainment for your research

- Manuscript accessibility in different formats

( Pdf, E-pub, Full Text, Audio)

- Unceasing customer service

Track the below URL for one-step submission

https://juniperpublishers.com/online-submission.php 